\title{
What to Offshore, What to Produce at Home? A Methodology
}

\author{
Marco Semini $^{1}$, Børge Sjøbakk ${ }^{1}$, and Erlend Alfnes ${ }^{2}$ \\ ${ }^{1}$ SINTEF Technology and Society, Industrial Management, \\ P.O. Box 4760 Sluppen, N-7465 Trondheim, Norway \\ \{marco.semini, borge.sjobakk\} @sintef . no \\ ${ }^{2}$ Department of Production and Quality Engineering, \\ Norwegian University of Science and Technology, NTNU \\ erlend.alfnes@ntnu.no
}

\begin{abstract}
Ever-increasing cost pressure and global competition has forced many Western manufacturing companies to offshore some or all of their production; i.e. to establish a manufacturing operation/facility in a low-cost country that replaces a facility in the country of origin. Literature concludes, however, that businesses do not make offshoring decisions in a systematic manner. This emphasizes the need for models, methodologies and tools supporting companies in making sound offshoring decisions. This paper proposes such a methodology for one of the crucial questions many offshoring companies face: For which products should production be offshored, for which should it be kept back? The proposed methodology consists of five steps: (1) Identify constants and variables (scoping); (2) Determine and characterize product groups; (3) Perform a strategic (qualitative) analysis; (4) Perform a financial (quantitative) analysis; and (5) Take a decision. The paper briefly describes each step, with a focus on the first three steps.
\end{abstract}

Keywords: Offshoring, facility strategy, global manufacturing, methodology.

\section{Introduction}

Ever-increasing cost pressure and global competition has forced many Western manufacturing companies to offshore, i.e. move some or all of their operations to low-cost countries, such as China or India, where manual labor continues to be as much as ten times cheaper than in Western Europe or the U.S. Besides lower factor costs, decisions to offshore are usually driven by closeness to (new) markets; access to foreign distribution channels, materials and goods; and securing of knowledge (Kinkel and Maloca 2009).

Offshoring is a highly complex process which entails a vast amount of decisions to be taken. In fact, most - if not all - decision categories within operations strategy as identified by Beckman and Rosenfield (2008) need to be addressed: Vertical integration, process technology, capacity, facilities, sourcing, business processes and policies, supply chain coordination, information technology and operations capabilities 
development. When a company has decided to engage in offshoring, making good decisions in such strategic areas will significantly impact whether the company will fail or succeed with the endeavor. Literature concludes, however, that "businesses don't make decisions about offshoring systematically enough" (Aron and Singh 2005). At the same time, literature aiming to help companies address offshoringrelated issues is scarce. This emphasizes the need for models, methodologies and tools supporting companies in making sound offshoring-related decisions.

This paper proposes a methodology for a crucial question many offshoring companies face: For which products should production be transferred to a low-cost facility, for which should it be kept back? In other words, should some products still be produced at the domestic plant, and - if so - which? This is a complex and difficult decision affecting many operations strategy decision categories, short-term and long-term considerations can pull in different directions, and it is highly affected not only by business-economical, but also political and personal considerations. The authors take the stance that a structured, rational and holistic approach to this decision increases the chance that it supports sustainable development of the business and reduces short-term focused, opportunistic behavior.

The remainder of this paper is structured as follows: First, the research method employed is described briefly. This is followed by a chapter briefly reviewing relevant literature and concluding that there is a need for more practical guidelines and methodologies on which products to produce where. Thereafter, we present the case company, i.e. the problem holder together which the proposed methodology was developed. Next, the five-step methodology is described, with focus on how the first three steps were carried out together with the case company. Finally, conclusions, including limitations and opportunities for further research are presented.

\section{Research Method}

The proposed methodology has been developed through utilizing the action research method. In action research, one seeks to generate new knowledge for both a problem owner and an action researcher through doing collaborative problem solving while having a research interest in mind (Greenwood and Levin 2007). As such, action research relies on the researcher(s) actively taking part in the context of his/her research interest area, offering a good insight to the problem and the problem holder (Gummesson 1991). This approach differs from many other research methods, which typically investigate the problem from the outside.

Like any other research method, action research has some shortcomings, especially regarding the reliability of the results. We acknowledge that the idiosyncratic context of the researchers and the problem holder impede the possibility to fully replicate the research and its results. Therefore, in order to achieve as high reliability as possible, we have documented the researchers' relation to the problem holder and how the methodology was developed (see chapter 4 and 5, respectively). 


\section{The Product Offshoring Decision}

Faced with significantly lower factor costs; closeness to new markets; access to foreign distribution channels, materials and goods; and securing of knowledge many companies choose to relocate parts their production (Kinkel and Maloca 2009). When making this decision, a company has multiple alternatives. It may choose to keep the production internally or have an external actor take on the responsibility, and the production may be either domestic or international (Monczka et al. 2005, Jahns et al. 2006). When activities are kept within the company, but moved to foreign markets, the term "captive offshoring" (Monczka et al. 2005), or just "offshoring", is used. For the purpose of this paper, we define "offshoring" as the situation of establishing a manufacturing operation in a low-labor-cost country that replaces a facility in a high-wage country (Hogan, 2004).

Relevant literature regarding offshoring encompass topics such as empirical investigations of how offshoring and outsourcing decisions are made (e.g. Lewin and Peeters 2006, Kedia and Mukherjee 2009) and the extent of offshoring in practice (e.g. Mol et al. 2004, Lewin and Peeters 2006, Kinkel and Maloca 2009); design and configuration of global manufacturing networks (e.g. Ferdows 1997); the importance of co-locating functions (e.g. Bartmess and Cerny 1993, Ulrich and Ellison 2005); global versus local sourcing (e.g. Kotabe and Murray 2004, Gelderman and Semeijn 2006, Trautmann et al. 2009); capacity expansion (e.g. Julka et al. 2007) and facility location (e.g. Dou and Sarkis 2010, Kedia and Mukherjee 2009). Several authors concentrate on the drivers and risk of offshoring (Schoenherr et al. 2008; Lampel and Bhalla 2011) - often, they take a stance for or against the necessity of offshoring. Some authors discuss the common pitfalls in offshoring (Aron and Singh 2005). They find that companies tend to focus too much on location and factor costs, do not evaluate all risk factors, and think that it is a matter of all or nothing.

Our review of the literature revealed some guidelines and methodologies supporting the relocation of production. However, such methodologies typically consider the make-or-buy decision and the logic of outsourcing (i.e. transferring production to an external actor) (e.g. Cousins, Lamming et al. 2008; Dou and Sarkis 2009; Tayles and Drury 2001), together with capacity strategy issues (e.g. Slack and Lewis 2008). Common for these methodologies is that they typically do not consider all product characteristics that may influence the offshoring decision. As such, there is a need to combine existing guidelines and methodologies on offshoring/outsourcing with other relevant literature in order to reach a structured, rational and holistic approach to the decision of what to produce where.

\section{The Case Company}

The present research has been carried out in collaboration with a Norwegian manufacturing plant. The plant designs, produces and delivers electronic high-tech equipment for the maritime industry worldwide. The total yearly production volume is approximately 60'000-70'000 items, delivered directly to shipyards, to suppliers of the yards 
and - in the aftermarket - to shipowners for repairs and upgrades. The market is constantly moving more to the East, especially the shipbuilding nations China and Korea, but there are still considerable volumes sent to European locations as well.

Until 2008, all production of these items was performed by the Norwegian plant. There is, however, an increasing need to reduce costs and follow the market to stay competitive in an increasingly global and fierce competition. This made the case company establish a manufacturing facility in the Shanghai area. In the process of transferring operations to this plant, the company realized that deciding which products to offshore involves trade-offs of more than costs and other easily quantifiable and comparable factors. It was concerned with a holistic, thorough analysis of all relevant aspects. The plant raised this issue to the authors, requesting a practical, but still systematic approach to decide which products to offshore, which to keep back. It should provide the managers with arguments supporting their decisions and, thereby, increase their confidence in them. It led the researchers to the development of the methodology presented in this paper, which is further described in the next chapter.

\section{$5 \quad$ A Methodology for Product Offshoring}

As explained, the purpose of the proposed methodology is to guide manufacturing plants in deciding which products to transfer to foreign subsidiaries and which to keep producing at the domestic plant. It has been developed for and tested at the case company presented, and it is therefore presented here by reporting its use in this context. In order to assure a comprehensive assessment, we considered it as important that all relevant business functions at the case company were represented when we performed critical steps in the methodology, such as production, product development, process development, purchasing and marketing/sales. The methodology consists of the following steps, which will be described below: (1) identify constants and variables (scoping); (2) determine and characterize product groups; (3) perform a strategic (qualitative) analysis; (4) perform a financial (quantitative) analysis; and (5) take a decision.

Step 1: Identify Constants and Variables (Scoping). First, we had to make sure all involved parties agreed on contextual parameters (fixed), decision variables (to be decided upon), and consequences of the decision (indirect decision variables). This is important in order to focus the assessment on the key question; avoiding circular argumentation and assuring that all parties base it on the same premises. In particular, the following was considered as fixed framework conditions within the present methodology: Macro-economic factors and developments, business strategy, product specter and product/market characteristics, available process technologies for these products (e.g., level of automation), as well as plant locations and overall plantlocational characteristics such as culture and industrial traditions. Overall business functions performed at each plant were also considered as given. For example, product and process development were assumed to be located in Norway, sourcing of mechanical components in China and distribution at both plants. 
Furthermore, we selected a range of products for which the offshoring question was particularly relevant, and we clearly demarcated which steps of the production process were included in the analysis, i.e. were candidates for offshoring (e.g. assembly). These products/process steps did not share materials or resources with the remaining products and process steps, for which we considered the location to be given. The decision variables were thus where to locate the selected process steps for the selected product range. Finally, we considered plant capacities, equipment and capabilities to a reasonable degree variable and depending on the decisions variables.

Step 2: Determine and Characterize Product Groups. The degree to which offshoring leads to benefits or implies risks depends on product characteristics. A basic element of the proposed methodology is therefore that it matches product characteristics to plant-locational characteristics. We have compiled a "checklist" of relevant product characteristics (Table 1). Based on this "checklist", we defined a number of product groups, each of which was largely homogeneous with respect to such characteristics. Group technology (Burbidge 1975) can provide the theoretical foundation for this. For each such product group, it should be possible to determine a suitable production location. As we realized, it was crucial to assure a common understanding of these product groups, if a consensus was to be achieved on where to produce them.

Table 1. Product characteristics of relevance when deciding whether to offshore or not

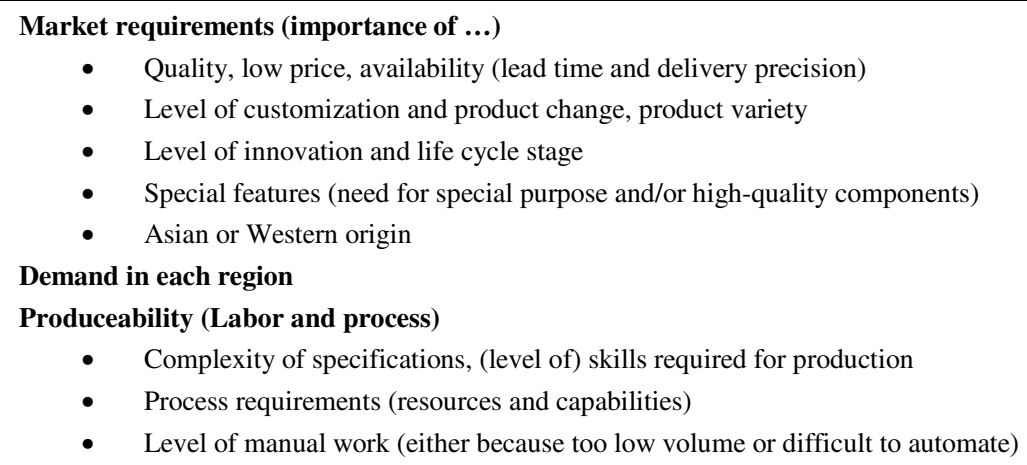

Unit Transportation costs, inclusive taxes and tariffs

Inventory carrying costs (heavily affected by product value)

Required raw materials and components

Step 3: Perform a Strategic (Qualitative) Analysis. In this step, we qualitatively assessed the consequences of offshoring each of the identified product groups. We compiled a "checklist" of relevant aspects (Table 2) and used it to compare offshoring to continued domestic production. This was done in a workshop with key informants from the case company. In a combination of group and plenary work, we gave each aspect of Table 2 a score, separately for each product group. This led to fruitful discussions and identification of key arguments for and against offshoring. It also led to 
a preliminary conclusion for each product group. We then combined the results and assessed the resulting scenario as a whole with respect to shared materials, resources and capabilities.

Table 2. Aspects affecting the product offshoring decision

Factor costs

\section{Outbound logistics}

\section{Plant and equipment utilization}

Plant capabilities

\author{
Inbound logis- \\ tics (purchas- \\ ing)
}

\section{Transfer and start-up costs}

\section{Proximity to product devel- opment}

\section{Intellectual property}

\section{Other}

How are factor costs affected? Direct and indirect labor cost seems to be the most common offshoring driver (Kinkel \& Maloca 2009). Other factor costs include material, capital and energy. Factor costs are often too significant to stay in a developed market and remain competitive (Beckman and Rosenfield 2008).

How is distribution affected, in terms of transportation costs, lead times, responsiveness, delivery precision, import taxes and tariffs, inventory carrying costs and value chain coordination? Whether the effects are positive or negative depends highly on the location of the main market. Market proximity is an important driver for offshoring (Kinkel \& Maloca 2009).

How is capacity utilization at each plant affected if the products are offshored? How easily can capacities be adapted to production volumes (flexible/inflexible resources)? Can plant overhead costs be justified for such volumes, if this is deemed necessary? It may be easier to argue for offshoring if capacity is well-utilized at the domestic plant.

How capable is the foreign plant of producing products with the given specifications and process requirements? The more complex the specifications/process, the higher typically is the level of skills and competences required. The ability to produce the required quality also needs to be considered, as well as, for example, labor effectiveness and flexibility.

How is inbound logistics affected? This aspect addresses the acquisition of raw materials and components. How are the costs, lead times, availabilities and responsiveness of potential suppliers to the foreign plant? How is product quality, in terms of functionality, robustness and health and environment? The costs needed to assure a satisfactory level of quality also need to be considered.

What are the transfer and start-up costs? The costs and challenges associated with moving and investing in equipment, ramping up production, capturing and transferring knowledge, establishing organizational structures and policies, selecting suppliers etc. may vary with different offshoring alternatives. Companies seem to underestimate such costs.

What is the risk of hampering innovation and customization due to distance between product development and production? Geographic dispersion can make communication more difficult. The higher the need for informal, "unstructured" technical dialogue, the more important is geographical proximity between production and product development.

What is the risk of intellectual property leaking and competitors building similar products, in turn reducing the company's competitive advantage? Even in captive offshoring, sensitive information and knowledge can leak through employee turnover. Employee turnover rates, intellectual property rights legislation in the foreign country and how to safely transfer specifications need to be considered.

Additional aspects of relevance may be identified in each particular case. In our study, the following issues were brought up: Market capturing/positioning; problems with "bringing home profit", i.e. transferring profit back to the home country; customer requests for price reductions due to production in low-cost country, or even customer refusals to buy such products. 
Step 4: Perform a Financial (Quantitative) Analysis. In step 4, a quantitative cost analysis is performed. While ideally, all relevant costs should be included (see Platts and Song 2010 for an overview), such an analysis in practice often focuses on cost types that can be reasonably well estimated, such as direct costs and some types of indirect costs. While it must be kept in mind that such easily quantifiable costs only stand for a part of the total cost of offshoring, a quantitative analysis can still provide a strong argument for a decision and increase confidence in it.

Step 5: Take a Decision. In combination, the results from the qualitative and quantitative assessment should provide a solid basis for the management board to take the final decision. It should however be kept in mind that only offshoring is considered, with plenty of framework conditions considered as given (as specified in step 1). Offshoring should be compared to other cost-reducing initiatives, such as automation and other process improvements at the domestic plant, product redesign according to design for manufacturing principles, product outsourcing or phasing-out etc.

\section{Conclusions}

This paper has presented a methodology for taking sound product offshoring decisions. It can be considered as a standardization of a strategy process. It must be repeated regularly as relevant aspects of the business and environment, such as those identified in step 1, change. It should also be kept in mind that in general, there is not one correct answer to the offshoring question. Competitive advantage comes not only from making good offshoring decisions, but equally from how these are implemented.

Feedback from the case company's managers supports the usefulness and validity of the proposed methodology. Some limitations still need to be mentioned. First, it has so far been mainly developed for and tested at a single case company; there is a need for additional case studies and subsequent improvement of the methodology. Second, it must be emphasized that it is a heuristic, i.e. it does not guarantee to find the "best" solution. It puts emphasis on ease of application and fostering companywide awareness of the trade-offs in offshoring decisions.

Acknowledgements. We thank the MARGIN project and the SFI Norman research program for support of the research presented in this paper.

\section{References}

Aron, R., Singh, J.V.: Getting Offshoring Right. Harvard Bus. Rev. 83(12), 135-143 (2005)

Bartmess, A., Cerny, K.: Building Competitive Advantage through a Global Network of Capabilities. Calif. Manage. Rev. 35(2), 78-103 (1993)

Beckman, S.L., Rosenfield, D.B.: Operations Strategy: Competing in the 21st Century. McGraw-Hill/Irwin, Boston (2008)

Burbidge, J.L.: The Introduction of Group Technology. Heinemann, London (1975) 
Cousins, P., et al.: Strategic Supply Management: Principles, Theories and Practice. Prentice Hall (2008)

Dou, Y.J., Sarkis, J.: A Joint Location and Outsourcing Sustainability Analysis for a Strategic Offshoring Decision. Int. J. Prod. Res. 48(2), 567-592 (2010)

Ferdows, K.: Making the Most of Foreign Factories. Harvard Bus. Rev. 75(2), 73-88 (1997)

Gelderman, C.J., Semeijn, J.: Managing the Global Supply Base through Purchasing Portfolio Management. J. Purch. Supply Manag. 12(4), 209-217 (2006)

Greenwood, D., Levin, M.: Introduction to Action Research, 2nd edn. Sage Publications, Thousand Oaks (2007)

Gummesson, E.: Qualitative Methods in Management Research. Sage Publications, Inc. (1991)

Hogan, G.: Going Offshore's Easy Right? Manuf. Eng., 75-84 (December 2004)

Jahns, C., Hartmann, E., Bals, L.: Offshoring: Dimensions and Diffusion of a New Business Concept. J. Purch. Supply Manag. 12(4), 218-231 (2006)

Julka, N., et al.: A Review of Multi-Factor Capacity Expansion Models for Manufacturing Plants: Searching for a Holistic Decision Aid. Int. J. Prod. Econ. 106(2), 607-621 (2007)

Kedia, B.L., Mukherjee, D.: Understanding Offshoring: A Research Framework Based on Disintegration, Location and Externalization Advantages. J. World Bus. 44(3), 250-261 (2009)

Kinkel, S., Maloca, S.: Drivers and Antecedents of Manufacturing Offshoring and Backshoring-a German Perspective. J. Purch. Supply Manag. 15(3), 154-165 (2009)

Kotabe, M., Murray, J.Y.: Global Sourcing Strategy and Sustainable Competitive Advantage. Ind. Market. Manag. 33, 7-14 (2004)

Lampel, J., Bhalla, A.: Living with Offshoring: The Impact of Offshoring on the Evolution of Organizational Configurations. J. World Bus. 46(3), 346-358 (2011)

Lewin, A.Y., Peeters, C.: Offshoring Work: Business Hype or the Onset of Fundamental Transformation? Long Range Plann. 39(3), 221-239 (2006)

Mol, M.J., et al.: A Technological Contingency Perspective on the Depth and Scope of International Outsourcing. Journal of International Management 10(2), 287-305 (2004)

Monczka, R.M., et al.: Outsourcing Strategically for Sustainable Competitive Advantage. CAPS Research Report. 1, 99 (2005)

Platts, K.W., Song, N.: Overseas Sourcing Decisions - the Total Cost of Sourcing from China. Supply Chain Manag. 15(4), 320-331 (2010)

Schoenherr, T., Rao Tummala, V.M., Harrison, T.P.: Assessing Supply Chain Risks with the Analytic Hierarchy Process: Providing Decision Support for the Offshoring Decision by a Us Manufacturing Company. J. Purch. Supply Manag. 14(2), 100-111 (2008)

Slack, N., Lewis, M.: Operations Strategy, 2nd edn. Pearson Education, Harlow (2008)

Tayles, M., Drury, C.: Moving from Make/Buy to Strategic Sourcing: The Outsource Decision Process. Long Range Plann. 34(5), 605-622 (2001)

Trautmann, G., Bals, L., Hartmann, E.: Global Sourcing in Integrated Network Structures: The Case of Hybrid Purchasing Organizations. Journal of International Management 15(2), 194-208 (2009)

Ulrich, K.T., Ellison, D.J.: Beyond Make-Buy: Internalization and Integration of Design and Production. Prod. Oper. Manag. 14(3), 315-330 (2005) 